\title{
NK/T Lymphocytes and LMP1: An Update on the Interactions and Mechanisms of Regulation
}

\author{
Ladkani N*, Mammari N, Halabi MA \\ Medical Laboratory department, Holy Family University, Lebanon
}

*Corresponding author: Nazih Ladkani, Holy Family University, Hadady Street, Ext/Fax 302, Lebanon, Tel: 9616642 250; Email: nlazkani94@hotmail.com

\section{Review Article}

Volume 2 Issue 6

Received Date: May 18, 2018

Published Date: May 25, 2018

\section{Abstract}

Epstein-Barr virus (EBV) is a strictly human virus of the family of Herpesviridae. It infects almost the entire population; the infection is often asymptomatic and benign. However, many studies show that this virus can also participate in the oncogenesis of various human malignancies of epithelial or lymphocytic origin. After the primary infection, EBV remains latent in the body. During this latency, some proteins are expressed, including LMP1 (latent membrane protein). This protein, located at the membrane level, induces several signalling pathways involved in the survival of the host cell. It is described as the major oncoprotein of EBV.

EBV-encoded latent membrane protein 1 is a multifunctional oncoprotein essential for transforming B lymphocytes into lymphoblastoid cell lines. The LMP1 gene, also referred to as BNLF1, encoding the LMP1 protein is relatively well conserved in its coding region, generally showing greater than $95 \%$ amino acid sequence identity between the different EBV isolates.

NK cells appear to play an important role in the early control of EBV infection in both mice and humans. Few studies were interested in the interaction between LMP1 and NK and T cells.

The aim of this review is to collect articles discussing the interaction between LMP1 and NK and T cells in order to describe the mechanisms of control of LMP1 by the NK/T cells and how LMP1 can regulate and promote them.

Keywords: EBV; LMP1; NK cell; T Lymphocytes; Extranodal NK/T-cell lymphoma

\section{Introduction}

Epstein-Barr virus (EBV) is a herpesvirus infecting more than $95 \%$ of the adult population. It is the first human virus known to be associated with human cancers where also the latent infection by this virus poses a public health burden worldwide [1]. EBV generally infects B cells via CD21 on the cell surface [2,3]. Nevertheless, it can also infect $\mathrm{T}$ or natural killer (NK) cells by unknown, CD21independent mechanisms [4]. 
Blood circulating lymphocytes are constituents of the immune system that defends the host against attack by viral, bacterial or parasitic pathogens, as well as against cancer. Lymphocytes are generally classified as T, B and NK lymphocytes. T and B lymphocytes are effectors of adaptive immunity, while NK cells are involved in the non-specific immune response. Therefore, NK cells differ from $\mathrm{T}$ and $\mathrm{B}$ cells by the permanent presence of $\mathrm{a}$ substantial fraction of educated sensitized cells [5]. NK cells contribute to the control of cancers and infections through the production of pro-inflammatory cytokines and the destruction of damaged, dysfunctional or infected host cells via cytotoxic activity [6]. They constitute about $10 \%$ of peripheral blood mononuclear cells (PBMCs).NK cells have receptors for cytokines such as interleukin (IL)12, IL-15, IL-18 and IL-2 [7].

EBV which infects NK cells can cause extranodal NK/Tcell nasal type lymphoma (ENKL), aggressive NK-cell leukemia (ANKL), EBV positive peripheral T-cell lymphoma, systemic EBV-positive T-cell lymphoma of childhood, and chronic active EBV infection (CAEBV) [810].

\section{LMP1 Protein}

The LMP1 viral protein is described as being involved in the process of the immortalization of cells by EBV, because of its ability to transform cells. A study performed by Izumi et al., focused on cells expressing LMP1 which are subsequently injected into nude mouse which induced the appearance of tumors. In addition, the LMP1 protein has been identified in biopsies of patients with LH (Hodgkin's lymphoma) or NPC (Nasopharyngeal carcinoma) [11]. This confirms the implication of LMP1 in diseases associated with EBV. LMP1 is a key modulator of cell signaling, inducing the expression of a number of antiapoptotic proteins including Bcl2 and A20 (TNFAIP3) $[12,13]$. Further characterization of the structure confirmed that LMP1 is a $63 \mathrm{kDa}$ membrane protein composed of 386 aa. It defines three distinct domains: the tail cytoplasmic amino-terminal (1-23 aa) which binds to the plasma membrane and directs the protein, six hydrophobic transmembrane loops (24-186 aa) that are involved in homo-oligomerization and self-aggregation, and some elongated cytoplasmic carboxy-terminal (187$386 \mathrm{aa}$ ) that controls most of the signaling activity of the molecule. Mutational analyses of LMP1 indicate that the cytoplasmic C-terminal part and the transmembrane domain 1 (TM1) are essential for B-cell transformation $[14,15]$.

\section{Role of NK Cells in EBV Control}

NK cells appear to play an important role in the early control of the herpes virus infection in both mice and humans $[16,17]$. This role seems to be less crucial for infection control by herpes virus-2 MHV 68 in mice [18]. The number of NK cells (but not CD1-restricted NKT cells) is increased in the patients' blood during NMI. In a small study on patients with CD56brighta EBV primary infection, a relative increase of the type has been observed.

The expression of certain molecules in EBV infected cells may play an indirect role in NF-? B activation. EBV $\mathrm{T} / \mathrm{NK}$ cell line TNF-alfa product, activates NF-? $\mathrm{B}$ in $\mathrm{T}$ and Nk cells [19]. The concentration of TNF-alfa in the serum was elevated in patients with CAEBV.

TNF-alfa stimulates EBV-T/NK cells in an autocrine way which induces their survival. In addition, EBV infection induces the expression of the CD40 and CD154 co-stimulators which are expressed on the surface of EBV$\mathrm{T} / \mathrm{Nk}$ cells $[20,21]$. The survival of these cells is provided by the CD40 ligand in an autocrine manner [20,21].

In addition, EBV infection induces the expression of CD137 on the surface of $T$ cells which triggers antiapoptotic signalling [22]. Since NF- $\mathrm{KB}$ can be activated downstream of CD40 and CD137, the expression of these two co-stimulators may play a role in the activation of NF$\kappa B$ in EBV-T/NK cells. Honami Takada et al, demonstrates that EBV infection protects infected cells from apoptosis [23]. Cytidine deaminase (AID) acts as a DNA and RNA editor, its expression induces a genomic mutation that causes the development of B-cell lymphoma. Active NF-kB in EBV T/NK cell line can lead to a positive regulation of AID which in turn can contribute to the induction of EBV [23].

\section{Expression of LMP1 and Function of T and NK Lymphocytes}

Studies on the role of LMP1 expression in T cells are limited to in vitro models, such as the expression of LMP1 in EBV-negative lymphoblastic T-cell lines [24-26]. Very few studies were performed on NK cells. An initial observation of an in vitro infection of these EBV lineages led to an increase in TNF- $\alpha$ expression; it was then demonstrated that the responsible protein was LMP1 [26]. 
Another study showed that the LMP1 protein that regulates the proliferation of CAEBV-derived cell lines did not play a role in the proliferation of EBV-negative cell lines [27]. The study has shown that LMP1 requires other factors to induce the proliferation of EBV-infected cells.

Hideyuki Ishii et al, demonstrated that monocytes stimulate the proliferation and expression of LMP1 in SNK6 and KAI3 cells from patients with NNKTL and patients with severe mosquito allergy, respectively, by cell-cell contact. IP-10 (IFN- $\gamma$ inducible protein-10) produced by EBV-positive cells attracts monocytes that come into contact with lymphoma cells. LMP1 induces the production of IP-10 by NNKTL cells which attract monocytes. This attraction stimulates the proliferation and expression of LMP1 in NNKTL cells via the membrane bound IL-15 [28].

In addition, EBV promotes the expression of CD137 which after stimulation by its ligands inhibits the death of EBV positive-T/NK cells [22]. In vitro IL-2 treatment enhances the expression of CD137 in EBV-positive cells. Takahara, et al., shows that IL-2 increases the expression of LMP1 in ENKL (PMID: 17013900). Mayumi Yoshimori, et al., suggests that LMP1 induces the synthesis of IL-2 that stimulates the expression of CD137 [22]. LMP1 induces expression of CD137 through AP-1 and NF- $\mathrm{kB}$ [29].

\section{Conclusion}

While it is certain that EBV is associated with cancer, one of the recurring questions is how it works and whether it is responsible for tumorigenesis. This review underlines the main mechanisms of interaction.

LMP1 induces the proliferation of EBV+ NK/T cells but it may not play this role in EBV negative cell line. In EBV+ NK/T cells LMP1 induces the production of IP-10 which attracts Monocytes which in turn activate the expression of LMP1 by IL-15. EBV induces the expression of CD137 which inhibit the death of NK/T cells. EBV+ NK/T cell line produces TNF-? which enhances the production of $\mathrm{NF}$ [? Bin an autocrine way. Subsequently Activated NF-? B leads to the regulation of AID which induces EBV gene expression.

Until today, only few reports are published. The aim of this review is to conduct a better understanding of the interaction mechanisms which may lead to better perspective on treatment development.

\section{References}

1. Fish K, Chen J, Longnecker R (2014) Epstein-Barr virus latent membrane protein $2 \mathrm{~A}$ enhances MYCdriven cell cycle progression in a mouse model of $B$ lymphoma. Blood 123(4): 530-540.

2. Fingeroth JD, Weis JJ, Tedder TF, Strominger JL, Biro $\mathrm{PA}$, et al. (1984) Epstein-Barr virus receptor of human B lymphocytes is the C3d receptor CR2. Proc Natl Acad Sci U S A 81(14): 4510-4514.

3. Nemerow GR, Wolfert R, Mcnaughton ME, Cooper NR (1985) Identification and characterization of the Epstein-Barr virus receptor on human B lymphocytes and its relationship to the C3d complement receptor (CR2). J Virol 55(2): 347-351.

4. Fox CP, Shannon-Lowe C, Rowe M (2011) Deciphering the role of Epstein-Barr virus in the pathogenesis of $\mathrm{T}$ and NK cell lymphoproliferations. Herpesviridae 2: 8.

5. Di Santo JP (2006) Natural killer cell developmental pathways: a question of balance. Annu Rev Immunol 24: 257-286.

6. Campbell KS, Hasegawa J (2013) Natural killer cell biology: an update and future directions. J Allergy Clin Immunol 132(3): 536-544.

7. Cooper MA, Fehniger TA, Caligiuri MA (2001) The biology of human natural killer-cell subsets. Trends Immunol 22(11): 633-640.

8. Rezk SA, Huang Q (2011) Extranodal NK/T-cell lymphoma, nasal type extensively involving the bone marrow. Int J Clin Exp Pathol 4(7): 713-717.

9. Rashidi A, Fisher SI (2016) EBV-associated aggressive natural killer cell leukemia. Blood 127: 2502.

10. Swerdlow SH, Campo E, Pileri SA, Harris NL, Stein H, et al. (2016) The 2016 revision of the World Health Organization classification of lymphoid neoplasms. Blood 127: 2375-2390.

11. Izumi KM, Kaye KM, KIEFF ED (1997) The EpsteinBarr virus LMP1 amino acid sequence that engages tumor necrosis factor receptor associated factors is critical for primary B lymphocyte growth transformation. Proc Natl Acad Sci USA 94(4): 14471452. 


\section{Virology \& Immunology Journal}

12. Henderson S, Rowe M, Gregory C, Croom-Carter D, Wang F, et al. (1991) Induction of bcl-2 expression by Epstein-Barr virus latent membrane protein 1 protects infected B cells from programmed cell death. Cell 65(7): 1107-1115.

13. Fukuda M, Longnecker R (2004) Latent membrane protein $2 \mathrm{~A}$ inhibits transforming growth factor-beta 1-induced apoptosis through the phosphatidylinositol 3-kinase/Akt pathway. J Virol 78(4): 1697-1705.

14. Kaye KM, Izumi KM, Kieff E (1993) Epstein-Barr virus latent membrane protein 1 is essential for Blymphocyte growth transformation. Proc Natl Acad Sci U S A 90(19): 9150-9154.

15. Kaye KM, Izumi KM, Mosialos G, Kieff E (1995) The Epstein-Barr virus LMP1 cytoplasmic carboxy terminus is essential for B-lymphocyte transformation; fibroblast cocultivation complements a critical function within the terminal 155 residues. J Virol 69(2): 675-683.

16. Braud VM, Tomasec P, Wilkinson GW (2002) Viral evasion of natural killer cells during human cytomegalovirus infection. Curr Top Microbiol Immunol 269: 117-129.

17. Chen H, Lee JM, Zong Y, Borowitz M, Ng MH, et al. (2001) Linkage between STAT regulation and Epstein-Barr virus gene expression in tumors. J Virol 75(6): 2929-2937.

18. Usherwood EJ, Meadows SK, Crist SG, Bellfy SC, Sentman CL (2005) Control of murine gamma herpes virus infection is independent of NK cells. Eur J Immunol 35(10): 2956-2961.

19. Luftig M, Yasui T, Soni V, Kang MS, Jacobson N, et al. (2004) Epstein-Barr virus latent infection membrane protein 1 TRAF-binding site induces NIK/IKK alphadependent noncanonical NF-kappaB activation. Proc Natl Acad Sci USA 101(1): 141-146.

20. Imadome K, Shirakata M, Shimizu N, Nonoyama S, Yamanashi Y (2003) CD40 ligand is a critical effector of Epstein-Barr virus in host cell survival and transformation. Proc Natl Acad Sci U S A 100(13): 7836-7840.

21. Imadome $\mathrm{K}$, Shimizu N, Arai A, Miura O, Watanabe K, et al. (2005) Co-expression of CD40 and CD40 ligand in Epstein-Barr virus-infected $\mathrm{T}$ and $\mathrm{NK}$ cells and their role in cell survival. J Infect Dis 192(8): 13401348.

22. Yoshimori M, Imadome K, Komatsu H, Wang L, Saitoh Y, et al. (2014) CD137 expression is induced by Epstein-Barr virus infection through LMP1 in T or NK cells and mediates survival promoting signals. PLoS One 9: e112564.

23. Takada H, Imadome KI, Shibayama H, Yoshimori M, Wang L, et al. (2017) Correction: EBV induces persistent NF-kB activation and contributes to survival of EBV-positive neoplastic T- or NK-cells. PLoS One 12(8): e0182682.

24. Chuang HC, Lay JD, Hsieh WC, Wang HC, Chang Y, et al. (2005) Epstein-Barr virus LMP1 inhibits the expression of SAP gene and upregulates Th1 cytokines in the pathogenesis of hemophagocytic syndrome. Blood 106(9): 3090-3096.

25. Kaplan J, Mastrangelo R, Peterson WD Jr (1974) Childhood lymphoblastic lymphoma, a cancer of thymus-derived lymphocytes. Cancer Res 34(3): 521525.

26. Lay JD, Chuang SE, Rowe M, Su IJ (2003) Epstein-barr virus latent membrane protein-1 mediates upregulation of tumor necrosis factor-alpha in EBVinfected T cells: implications for the pathogenesis of hemophagocytic syndrome. J Biomed Sci 10(1): 146155.

27. Ito $\mathrm{T}$, Kawazu $\mathrm{H}$, Murata $\mathrm{T}$, Iwata $\mathrm{S}$, Arakawa $\mathrm{S}$, et al. (2014) Role of latent membrane protein 1 in chronic active Epstein-Barr virus infection-derived T/NK-cell proliferation. Cancer Med 3(4): 787-795.

28. Ishii H, Takahara M, Nagato T, Kis LL, Nagy N, et al. (2012) Monocytes enhance cell proliferation and LMP1 expression of nasal natural killer/T-cell lymphoma cells by cell contact-dependent interaction through membrane-bound IL-15. Int J Cancer 130(1): 48-58.

29. Kim JO, Kim HW, Baek KM, Kang CY (2003) NFkappaB and AP-1 regulate activation-dependent CD137 (4-1BB) expression in $\mathrm{T}$ cells. FEBS Lett 541(1-3): 163-170. 